\title{
Resultados de um trabalho de parceria da Fundação Bradesco com as escolas públicas no Vale do Ribeira/SP
}

\author{
ROSE NEUBAUER* \\ YARA ESPOSITO** \\ ANA LUÍSA RESTANI*** \\ MARIA CRISTINA TELLES**** \\ ELZA MARIA GUERESCHI'***** \\ SILVIA ROBLES JUHAS ${ }^{* * * * * *}$
}

\section{RESUMO}

$\mathrm{O}$ artigo discute os resultados da avaliação do Projeto Piloto Educa+Açáo, desenvolvido em escolas públicas municipais de oito municípios do Vale do Ribeira/SP, em 2007 e 2008. A partir de uma parceria entre a Fundaçáo Bradesco, o Banco Bradesco, as Prefeituras e com apoio da Uniáo Nacional dos Dirigentes Municipais de Educaçáo (Undime), este projeto teve por objetivo a alfabetizaçáo nos dois primeiros anos do ensino fundamental (de nove anos), por meio da formação de professores para o uso de metodologia e material didático da Fundaçáo Bradesco. Os resultados obtidos na avaliação de Leitura indicaram que $50 \%$ dos alunos acertaram $73 \%$ ou mais das questóes da prova, e que $70 \%$ tiveram desempenho médio ou acima da média em

\footnotetext{
* Diretora Presidente do Instituto Protagonistés (protagonistes@protagonistes.org.br). ** Pesquisadora da Fundação Carlos Chagas e Consultora do projeto (yesposito@fcc.org.br). *** Superintendente Executiva da Fundação Bradesco (arestani@fundacaobradesco.org.br). **** Gerente do Departamento de Educação Básica da Fundaçáo Bradesco (ctelles@fundacaobradesco.org.br). ***** Gerente do Setor de Currículo da Fundação Bradesco (eguereschi@fundacaobradesco.org.br). ****** Coordenadora do Programa Educa+Açāo da Fundaçáo Bradesco (sjuhas@fundacaobradesco.org.br).
} 
Matemática, o que pode ser considerado extremamente satisfatório se comparado aos resultados alcançados pelos alunos em avaliaçóes estaduais e nacionais recentes. Por meio da análise estatística das variáveis consideradas significantes para diferenciar o desempenho de diferentes grupos de alunos, foi possível concluir que fatores como: a idade dos alunos, a frequência à pré-escola, o grau de escolaridade dos professores e a sua permanência durante os dois anos do projeto foram determinantes para os resultados alcançados.

Palavras-chave: Avaliaçáo da aprendizagem, Desempenho, Projeto Piloto Educa+Ação, Escolas públicas, Alunos.

\section{RESUMEN}

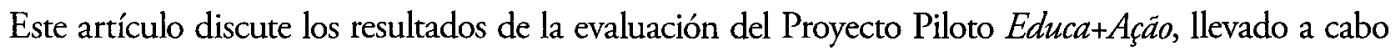
en 2007 y 2008 en escuelas públicas municipales de ocho municipios del Vale do Ribeira/SP. Fue realizado a partir de un trabajo conjunto entre la Fundación Bradesco, el Banco Bradesco y las Intendencias municipales y contó con el apoyo de la UNDIME (Unión Nacional de los Dirigentes Municipales de Educación). Este proyecto tuvo como objetivo la alfabetización, durante los dos primeros años de la enseñanza fundamental (nueve años), a través de la formación de profesores, para que usasen la metodología y el material didáctico de la Fundación Bradesco. Los resultados obtenidos en la evaluación de lectura indicaron que el $50 \%$ de los alumnos respondieron correctamente el $73 \%$ o más de los puntos de la prueba, y que el $70 \%$ tuvo un desempeńo medio o arriba de la media en matemática. Esto puede ser considerado extremadamente satisfactorio si se lo compara con los resultados alcanzados por los alumnos en recientes evaluaciones provinciales y nacionales. Por medio del análisis estadístico de las variables consideradas significativas para diferenciar el desempeño de distintos grupos de alumnos, fue posible concluir que factores como la edad, la asistencia al jardín de infantes, el grado de escolaridad de los profesores y la permanencia de los mismos durante los dos años del proyecto fueron determinantes para el logro de los resultados alcanzados.

Palabras clave: Evaluación del aprendizaje, Desempeño, Proyecto Piloto Educa+Ação, Escuelas públicas, Alumnos.

\section{ABSTRACT}

This article discusses the results of the Pilot Project Educa $+A c ̧ a ̈ o$ (Education \& Action), developed in 2007 and 2008 in public schools in eight districts of the Vale do Ribeira, in the state of São Paulo. Through a partnership between Bradesco Foundation, Bradesco Bank, the local governments, and with the support of UNDIME, this project aimed to achieve literacy in the first two years of basic education (nine years), by training teachers to use the methodology and teaching materials of the Bradesco Foundation. The results obtained in the reading assessment indicated that $50 \%$ of the students got $73 \%$ or more of the questions in the exam right, and that $70 \%$ were middle or above average in Mathematics, which can be considered very satisfactory if compared to the results achieved by students in recent state and national assessments. Through statistical analysis of the variables considered significant to differentiate the performance of different groups of students, the study came to the conclusion that factors such as student age, pre-school attendance, teachers' educational level and their permanence during the two years of the project were instrumental in the results achieved.

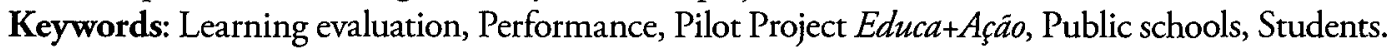




\section{APRESENTAÇÃO}

A Fundação Bradesco, há 52 anos, atua na educação, oferecendo educação escolar gratuita e de qualidade para a populaçáo economicamente desfavorecida e desprovida dos mais elementares serviços de assistência. Em escolas próprias, oferece educaçâo básica, cursos técnicos e profissionalizantes, além da escola virtual. Atendeu, em 2008, 110.415 alunos, sendo 49.534 da educação básica. Está presente em todos os Estados da Federação, assumindo a missáo de atuar como pólo gerador e multiplicador de educação e cultura e de legitimar a Organização Bradesco como empresa socialmente responsável.

Dessa forma, valendo-se das suas experiências bem-sucedidas, em parceria com o Banco Bradesco, lançou o Projeto Piloto Educa+Açáo, visando a integrar a iniciativa privada e o setor público municipal no esforço de elevar o padráo educacional dos alunos nas primeiras séries do ensino fundamental.

O Educa+Ação tem como objetivo oferecer condiçóes para que as crianças atendidas pela educaçáo pública aprendam a ler e escrever nos dois primeiros anos do ensino fundamental (de nove anos).

Para o desenvolvimento do Projeto Piloto, em 2007 e 2008, foram selecionados oito municípios do Vale do Ribeira (região com menor IDH de Sáo Paulo): Registro, Juquiá, Jacupiranga, Eldorado, Iguape, Sete Barras, Pariquera-Açu e Cajati. Em Registro, existe uma unidade escolar da Fundação Bradesco que atuou como apoio e orientaçáo ao trabalho desenvolvido. O projeto piloto, nesse período, atendeu 14 escolas, 48 professores e 1.108, alunos distribuídos em 48 classes.

Além do material didático para os alunos e do material pedagógico de apoio para o professor, as escolas receberam supervisão pedagógica sistemática, que aconteceu em momentos de formaçáo coletiva e em visitas às unidades escolares envolvidas. No período de implementaçáo do projeto piloto, ocorreram as seguintes açóes de formaçáo:

- Acompanhamento e orientação aos coordenadores pedagógicos.

- Capacitaçáo de professores e coordenadores nos diversos períodos de planejamento.

- Capacitação de professores e coordenadores em reunióes pedagógicas.

- Capacitaçáo em reunióes de HTPCs (Horas de Trabalho Pedagógico Coletivo) dos professores. 
Durante os dois anos do projeto piloto, instrumentos de sondagem de leitura e escrita foram elaborados e aplicados pela equipe de supervisão pedagógica da Fundaçáo Bradesco com o objetivo de avaliar as competências e habilidades adquiridas e compará-las às expectativas de aprendizagem propostas para o período avaliado.

Além desses instrumentos de sondagem utilizados com os alunos, em 2008 foi aplicada a Provinha Brasil, disponibilizada pelo MEC, para acompanhar o desenvolvimento da alfabetizaçáo e do letramento inicial.

\section{CARACTERÍSTICAS DA AVALIAÇÃO}

Para garantir a transparência e a fidedignidade dos resultados alcançados pelo projeto, foi contratada uma empresa com experiência na área de avaliação de projetos educacionais, o Instituto Protagonistés. Em razáo da diversidade de açóes desencadeadas, a avaliação externa buscou:

- Avaliar o desempenho dos estudantes em Língua Portuguesa (incluindo Redação) e Matemática.

- Mapear as percepçóes dos profissionais envolvidos (professores, coordenadores e diretores) quanto aos materiais distribuídos aos alunos, aos professores e nas salas de aula.

- Identificar as percepçóes dos profissionais envolvidos no que se refere à capacitaçâo para uso dos materiais e novas estratégias de ensino-aprendizagem.

- Identificar expectativas e percepçóes dos pais sobre mudanças nas práticas de ensino e no rendimento escolar de seus filhos.

Para tanto, foram propostos os seguintes instrumentos de avaliaçáo:

- Provas de avaliaçáo do desempenho: 1.057 alunos, em Língua Portuguesa (Prova de Leitura) e 1.059 alunos, em Matemática e Redação.

- Questionários para todos os professores, coordenadores e diretores focando prioritariamente a formação profissional; condiçóes básicas de trabalho na escola: infraestrutura, recursos pedagógicos disponíveis, horas de trabalho pedagógico; percepçôes sobre o impacto das ações do projeto no processo de gestáo, atuaçáo docente e no rendimento escolar; avaliação dos materiais e da capacitação recebidos.

- Entrevistas com todos os Secretários Municipais de Educação para averiguar as percepçóes sobre o impacto do projeto na gestáo, atuação docente e rendimento escolar dos alunos. 
- Grupo focal com 17 grupos (203 pais) buscando coletar: expectativas e atitudes em relação ao projeto; percepção a respeito das mudanças recentes nas práticas pedagógicas dos professores; impacto das mudanças no comportamento e rendimento escolar de seus filhos.

A elaboração das provas de Leitura e de Matemática foi realizada a partir de tabelas de especificação de habilidades e competências (selecionadas entre as definidas pelo Saeb, Saresp e Provinha Brasil). Assim, a prova de Leitura foi composta de 30 itens ou questóes, sendo 28 de múltipla escolha e duas questôes abertas. Uma destas desdobrou-se em subitens de modo que o total de pontos possíveis era 33. A prova de Matemática reuniu 14 questóes, a maioria aberta. Neste caso, também, três questões desdobraram-se em dois itens, possibilitando um máximo de 17 pontos nesta prova.

\section{RESULTADOS DOS DESEMPENHOS DOS ALUNOS}

\subsection{Prova de Leitura}

Foram consideradas válidas, para as análises estatísticas, as provas respondidas por 1.057 alunos. Para caracterizar o seu desempenho na prova de Leitura, dois procedimentos de análise estatística foram utilizados. No primeiro deles, foram excluídas das análises as questóes 12 e 28 (questóes abertas), procedendose a uma análise clássica dos itens da prova por meio de um software específico (Conventional Item and Test Analysis). A vantagem da utilizaçáo desse procedimento é que ele permite identificar exatamente qual foi a distribuiçáo das respostas dadas pelos alunos a cada uma das alternativas de cada item. No segundo procedimento, foram consideradas todas as questóes da prova, adotando-se como critério de apresentação da distribuiçáo o número e o percentual de respostas associadas às seguintes categorias: "acerto", "erro", e "em branco". Os resultados indicam que o número mínimo de acertos foi igual a $1 \mathrm{e}$, o máximo, a 33 pontos. A média de acertos do grupo total de participantes foi igual a 22,7 pontos o que corresponde a um percentual de acertos de cerca de 70\%. O desvio padráo apurado (6,4 pontos) indica que o grupo de alunos era relativamente heterogêneo em termos de desempenho.

Na tabela 1, são sintetizadas as principais estatísticas da prova de Leitura. 
Tabela 1 - Estatísticas gerais da prova de Leitura

\begin{tabular}{llll}
\hline Média & 22,7 & $70 \%$ acertos \\
\hline Percentiles & & \\
P 25 & 18 & & $55 \%$ acertos \\
P 50 & 24 & Mediana & $73 \%$ acertos \\
P 75 & 28 & $85 \%$ acertos \\
\hline
\end{tabular}

O valor da mediana (24 pontos), superior ao da média $(22,7)$, indica que 50\% dos alunos acertaram $73 \%$ ou mais dos itens da prova. A distribuiçáo dos alunos por percentual de acertos (Gráfico 1) resulta numa curva de notas enviesada à direita e mostra que o conjunto total dos participantes realizou a prova com relativa facilidade. É possível afirmar, portanto, que $70 \%$ dos alunos tiveram um desempenho variando entre bom a excelente quanto à aquisiçáo de competências e habilidades esperadas ao final dessa etapa de escolarização.

Gráfico 1 - Distribuição do número de acertos na prova de Leitura

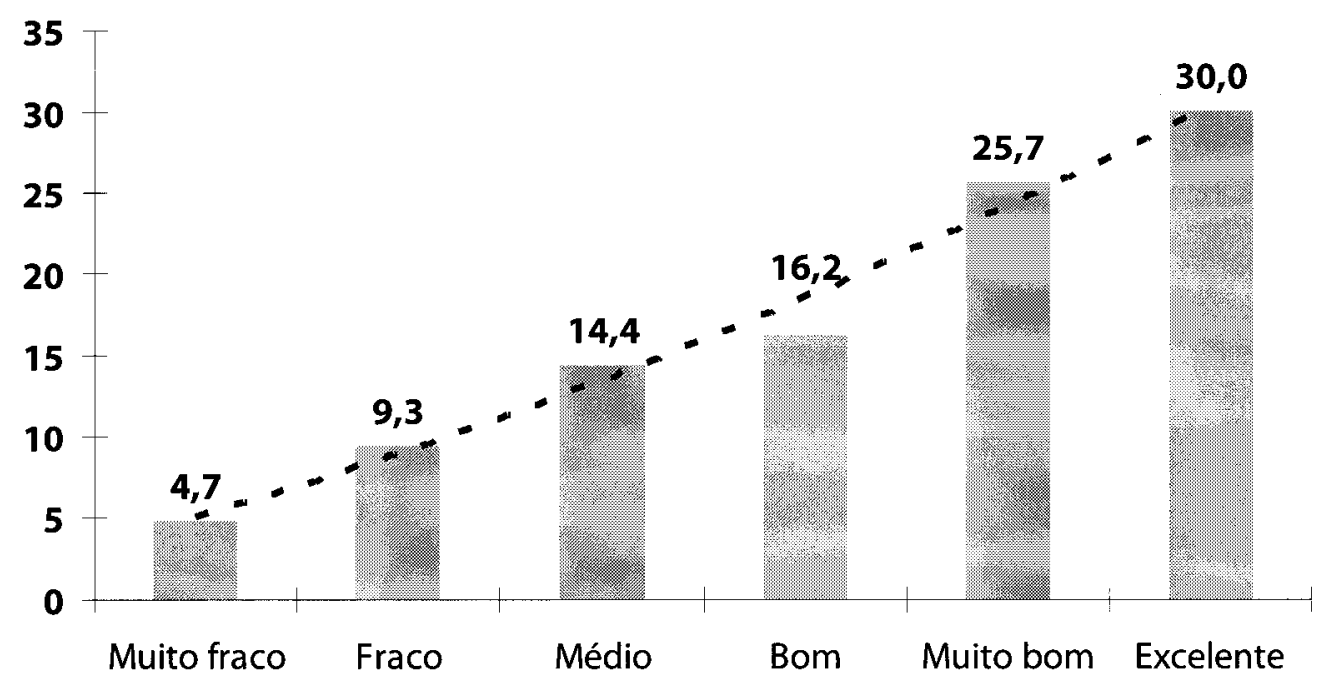


A matriz de competências e habilidades adotada para a elaboração das questōes incluídas na prova de Leitura baseou-se nas matrizes da Provinha Brasil e do Saresp, e buscava identificar o nível de conhecimento dos alunos sobre o sistema de escrita e a capacidade de ler com autonomia, ao final dos dois primeiros anos do ensino fundamental. Para assegurar que a prova fosse capaz de discriminar o desempenho de diferentes grupos de alunos das escolas, além de 24 itens similares aos da Provinha, acrescentou-se 6 outros à matriz, a fim de identificar alunos com excelente desempenho, o que aumentou o nível de dificuldade da prova. A matriz resultante está dividida em dois blocos de conteúdos: apropriaçáo do sistema de escrita e leitura, conforme tabela de descritores apresentada abaixo:

Tabela 2 - Descritores (competências e habilidades)

\begin{tabular}{|c|c|c|}
\hline Conteúdos & Competências e habilidades (descritores) & Itens de $\mathrm{n}^{\circ}$ \\
\hline \multirow{11}{*}{$\begin{array}{l}\text { Apropriação do } \\
\text { sistema da } \\
\text { escrita }\end{array}$} & $\begin{array}{l}\text { D1. Diferenciar letras de outros sinais gráficos, como os } \\
\text { números, sinais de pontuação ou de outros sistemas } \\
\text { de representação. }\end{array}$ & 10 \\
\hline & D2. Identificar letras do alfabeto. & 3 \\
\hline & $\begin{array}{l}\text { D3. Reconhecer palavra como unidade gráfica ou } \\
\text { semântica. }\end{array}$ & 2,9 \\
\hline & D4. Distinguir diferentes tipos de letras. & 17 \\
\hline & $\begin{array}{l}\text { D5. Identificar silabas e/ou letras de palavras ouvidas } \\
\text { e/ou lidas. }\end{array}$ & $6,14,11$ \\
\hline & D6. Identificar relações fonema/grafema (som/letra). & 16 \\
\hline & D7. Ler palavras. & $1,2,4,5,7,8,15$ \\
\hline & D8. Localizar informação em textos. & $19,20,23,28$ \\
\hline & D9. Inferir informação. & 24,26 \\
\hline & D10. Identificar assunto de um texto lido ou ouvido. & 25,27 \\
\hline & $\begin{array}{l}\text { D11. Antecipar assunto do texto com base em título, } \\
\text { subtítulo, imagens. }\end{array}$ & 27,29 \\
\hline \multirow{3}{*}{$\begin{array}{l}\text { Compreensão de } \\
\text { Leitura }\end{array}$} & $\begin{array}{l}\text { D12. Identificar a finalidade do texto pelo reconhecimento } \\
\text { do suporte, do gênero e das características gráficas. }\end{array}$ & $13,18,22,29$ \\
\hline & D13. Reconhecer a ordem alfabética. & 12 \\
\hline & $\begin{array}{l}\text { D14. Identificar elementos que compõem a narrativa, } \\
\text { como tempo, espaço e personagem. }\end{array}$ & 21,30 \\
\hline
\end{tabular}


Os objetivos da análise de itens efetuada (Conventional Item and Test Analysis) foram: verificar a adequaçáo e qualidade dos itens, ou seja, avaliar se a prova elaborada era representativa dos conteúdos e habilidades que se pretendia avaliar; e analisar se o conjunto dos itens apresentava variaçōes quanto ao grau de dificuldade e de discriminação. Em outras palavras, buscou-se avaliar a capacidade da prova para separar grupos de estudantes com desempenhos diferentes. Para cada uma das questōes, calculou-se separadamente o percentual de acertos para a amostra total, assim como para o grupo superior e inferior de alunos, conforme definido no agrupamento das escolas. A diferença de desempenho entre os grupos extremos permitiu detectar o índice de discriminação de cada um dos itens e sua composição na organização da prova (Tabela 3).

Tabela 3 - Percentual de respostas certas por grupos de desempenho em Leitura

\begin{tabular}{|c|c|c|c|c|c|c|c|c|c|}
\hline \multirow{2}{*}{ Itens } & \multicolumn{2}{|c|}{ Inferior } & \multicolumn{2}{|c|}{ Intermediário } & \multicolumn{2}{|c|}{ Superior } & \multicolumn{2}{|c|}{ Total } & \multirow{2}{*}{$\begin{array}{c}\text { Diferença } \\
\%\end{array}$} \\
\hline & $n$ & $\%$ & $\mathbf{n}$ & $\%$ & $\mathbf{n}$ & $\%$ & $\mathbf{n}$ & $\%$ & \\
\hline$q 1$ & 260 & 87 & 441 & 100 & 312 & 99 & 1013 & 96 & 12 \\
\hline$q 2$ & 141 & 47 & 381 & 86 & 304 & 97 & 826 & 0 & 50 \\
\hline$q^{3}$ & 229 & 76 & 412 & 93 & 310 & 99 & 951 & 90 & 23 \\
\hline$q 4$ & 220 & 73 & 438 & 99 & 312 & 99 & 970 & 92 & 26 \\
\hline$q^{5}$ & 273 & 91 & 441 & 100 & 313 & 100 & 1027 & 97 & 9 \\
\hline q6 & 284 & 95 & 439 & 99 & 313 & 100 & 1036 & 98 & 5 \\
\hline q7 & 202 & 67 & 378 & 85 & 299 & 95 & 879 & 83 & 28 \\
\hline q8 & 227 & 76 & 430 & 97 & 309 & 98 & 966 & 91 & 22 \\
\hline$q 9$ & 179 & 60 & 390 & 88 & 308 & 98 & 877 & 83 & 38 \\
\hline$q 10$ & 207 & 69 & 408 & 92 & 305 & 97 & 920 & 87 & 28 \\
\hline $\mathrm{q} 11$ & 168 & 56 & 350 & 79 & 285 & 91 & 803 & 76 & 35 \\
\hline $\mathrm{q} 12$ & 32 & 11 & 148 & 33 & 240 & 76 & 420 & 40 & 65 \\
\hline$q 13$ & 110 & 37 & 315 & 71 & 301 & 96 & 726 & 69 & 59 \\
\hline q14 & 177 & 59 & 347 & 78 & 288 & 92 & 812 & 77 & 33 \\
\hline q15 & 217 & 72 & 411 & 93 & 290 & 92 & 918 & 87 & 20 \\
\hline$q 16$ & 237 & 79 & 421 & 95 & 311 & 99 & 969 & 92 & 20 \\
\hline $\mathrm{q} 17$ & 74 & 25 & 291 & 66 & 296 & 94 & 661 & 63 & 69 \\
\hline q18 & 108 & 36 & 237 & 54 & 238 & 76 & 583 & 55 & 40 \\
\hline q19 & 118 & 39 & 361 & 82 & 295 & 94 & 774 & 73 & 55 \\
\hline $\mathrm{q} 20$ & 123 & 41 & 367 & 83 & 309 & 98 & 799 & 76 & 57 \\
\hline$q 21$ & 56 & 19 & 212 & 48 & 269 & 86 & 537 & 51 & 67 \\
\hline$q 22$ & 71 & 24 & 191 & 43 & 209 & 67 & 471 & 45 & 43 \\
\hline$q 23$ & 47 & 16 & 172 & 39 & 231 & 74 & 450 & 43 & 58 \\
\hline$q 24$ & 75 & 25 & 298 & 67 & 301 & 96 & 674 & 64 & 71 \\
\hline$q 25$ & 105 & 35 & 273 & 62 & 260 & 83 & 638 & 60 & 48 \\
\hline$q 26$ & 90 & 30 & 213 & 48 & 194 & 62 & 497 & 47 & 32 \\
\hline$q 27$ & 92 & 31 & 105 & 24 & 194 & 62 & 391 & 37 & 31 \\
\hline q28a & 28 & 9 & 248 & 56 & 294 & 94 & 570 & 54 & 85 \\
\hline$q 28 b$ & 4 & 1 & 158 & 36 & 263 & 84 & 425 & 40 & 83 \\
\hline$q 28 c$ & 19 & 6 & 233 & 53 & 303 & 97 & 555 & 53 & 91 \\
\hline q28d & 14 & 5 & 224 & 51 & 308 & 98 & 546 & 52 & 93 \\
\hline q29 & 60 & 20 & 319 & 72 & 306 & 98 & 685 & 65 & 78 \\
\hline$q 30$ & 87 & 29 & 232 & 52 & 268 & 85 & 587 & 56 & 56 \\
\hline
\end{tabular}


O conjunto das estatísticas revelou uma prova bem balanceada com diversidade de desempenho no interior do grupo e a presença de itens com altos índices de discriminação, capazes de detectar essa diferença entre os grupos. Como mostra a tabela 4, para a amostra total, 9 itens foram resolvidos com muita facilidade pelos alunos (entre $86 \%$ e $100 \%$ dos estudantes acertaram esses itens), e 8 itens foram solucionados com relativa facilidade ( $66 \%$ a $85 \%$ de acertos). Um conjunto de 10 itens revelou-se de dificuldade média ( $51 \%$ a $65 \%$ de acertos) e 6 itens foram considerados difíceis para o grupo (36\% a $65 \%$ de acertos). Nenhuma questáo foi considerada bem ou muito difícil para o grupo de alunos como um todo, ou seja, para o conjunto da populaçáo pesquisada, nenhuma questáo teve menos de $16 \%$ de acertos. Entretanto, a distribuiçáo dos itens quanto à dificuldade mostra-se diferente quando se examina os resultados do grupo inferior. Para esse grupo 9 itens foram considerados bem difíceis e 6 muito difíceis (Tabela 4). No extremo oposto, encontra-se o grupo "superior" em termos de desempenho: 22 dos 33 itens da prova foram resolvidos com muita facilidade pelos alunos desse grupo; seis $(20,0 \%) \mathrm{com}$ facilidade e somente dois $(6,7 \%)$ com dificuldade mediana.

Tabela 4 - Classificação da dificuldade dos itens

\begin{tabular}{l|c|c|c|c|c}
\hline \multirow{2}{*}{ Classificação } & \multirow{2}{*}{$\begin{array}{c}\text { \% de } \\
\text { acertos }\end{array}$} & $\begin{array}{c}\text { No de } \\
\text { itens }\end{array}$ & Itens & $\begin{array}{c}\text { No de } \\
\text { itens }\end{array}$ & Itens \\
\hline Muito fácil & 86 a 100 & 9 & $1,3,4,5,6,8,10,15,16$ & 3 & $1,5,6$ \\
\hline Fácil & 66 a 85 & 8 & $2,7,9,11,13,14,19,20$ & 6 & $3,4,8,10,15,16$ \\
\hline $\begin{array}{l}\text { Média } \\
\text { dificuldade }\end{array}$ & 51 a 65 & 10 & $\begin{array}{r}17,18,21,24,25,28 \mathrm{a}, \\
28 c, 28 d, 29,56\end{array}$ & 4 & $7,9,11,14$ \\
\hline Difícil & 36 a 65 & 6 & $12,22,23,26,27,28 \mathrm{~b}$ & 5 & $2,13,18,19,20$ \\
\hline Bem difícil & 16 a 35 & 0 & & 9 & $\begin{array}{c}17,21,22,24,25,26,27, \\
29,30\end{array}$ \\
\hline Muito difícil & 0 a 15 & 0 & & 3 & $12,23,28 \mathrm{a}, 28 \mathrm{~b}, 28 \mathrm{c}, 28 \mathrm{~d}$ \\
\hline
\end{tabular}

\subsection{Prova de Redaçáo}

Estiveram presentes, no dia da aplicaçáo da prova de Redaçáo, 1.059 alunos, o que corresponde a 93,7\% dos participantes do projeto. Para a correção da Redação, selecionou-se, num primeiro momento, uma amostra das produçóes escritas, definindo-se, a partir dessa amostragem, categorias de análise que permitiu classificá-las em seis grupos, a saber: 
Grupo I - incluídas, neste primeiro grupo, as redaçôes em branco; as que evidenciavam ter havido cópia do enunciado e aquelas que náo permitiram aos avaliadores realizar uma classificaçáo.

Grupo II - composto por produçōes constituídas por uma única frase (uma "resposta telegráfica"), que remetia ao que havia sido solicitado nas instruçôes relativas à realização da tarefa: "Conte quem ganhou".

Grupo III - classificadas, neste grupo, as produçōes escritas nas quais os alunos atenderam à proposta ("Conte quem ganhou e diga por que isso aconteceu"), escrevendo uma resposta (frase ou frases), que envolvia apresentava uma explicação para as ações em que era possível observar, explícita ou implicitamente, certa continuidade de sentido e/ou articulaçáo entre os fatos.

Grupo IV - todas as produçóes que se constituíam em um texto (ou pré-texto) com algumas características de linguagem escrita e do gênero proposto (narrativa). Com mais de uma ou duas frases, nas quais se nota, explícita ou implicitamente, a tentativa de dar continuidade ou progressão ao texto. Não há, no entanto, unidade de sentido. Repetiçóes e/ou quebra de argumentos caracterizam as produçóes deste grupo.

Grupo V - os textos que apresentaram características de uma narrativa. $\mathrm{O}$ aluno revelou ter compreendido o que foi solicitado. Notam-se no texto: menção aos personagens, destaque para os dados da situaçáo, certo encaminhamento de ações, estabelecimento de relaçóes lógicas (causalidade), tentativa de introduçáo de diálogo.

Grupo VI - os textos incluídos neste grupo diferenciaram-se dos do grupo anterior (Grupo V) por apresentarem evidências de maior domínio e/ou familiaridade com as regras relativas à produçáo de redaçóes do gênero narrativa. Possuíam, também: certa originalidade, vocabulário diversificado, emprego mais frequente de adjetivos e presença de marcadores de tempo.

Os resultados obtidos por meio da classificação das redações permitem concluir que, semelhante ao que se se constatou na prova de Leitura, tratase de um grupo heterogêneo em termos do desenvolvimento do processo de letramento (Tabela 5). 
Tabela 5 - Distribuição do número e percentual de alunos classificados em cada um dos grupos

\begin{tabular}{c|c|c}
\hline Grupo & $\mathbf{n}$ & \% válidas \\
\hline I & 189 & 17,85 \\
\hline II & 143 & 13,50 \\
\hline III & 206 & 19,45 \\
\hline IV & 251 & 23,70 \\
\hline V & 177 & 16,71 \\
\hline VI & 93 & 8,78 \\
\hline Subtotal & 1059 & 100,00 \\
\hline Ausentes & 71 & \\
\hline Total & $\mathbf{1 1 3 0}$ & \\
\hline
\end{tabular}

Posteriormente, os alunos foram reagrupados náo só de acordo com a natureza dos textos, mas também pelo domínio ortográfico. O gráfico 2 mostra que $77 \%$ dos alunos escrevem com correspondência sonora/alfabética. Desses, $29 \%$ constroem pré-textos e $26 \%$ escrevem textos com características de narrativas; alguns com muita criatividade, relativo domínio de pontuação e poucas ou aceitáveis transgressóes gramaticais.

Gráfico 2 - Distribuição percentual dos alunos por desempenho nas categorias de análise de Redação

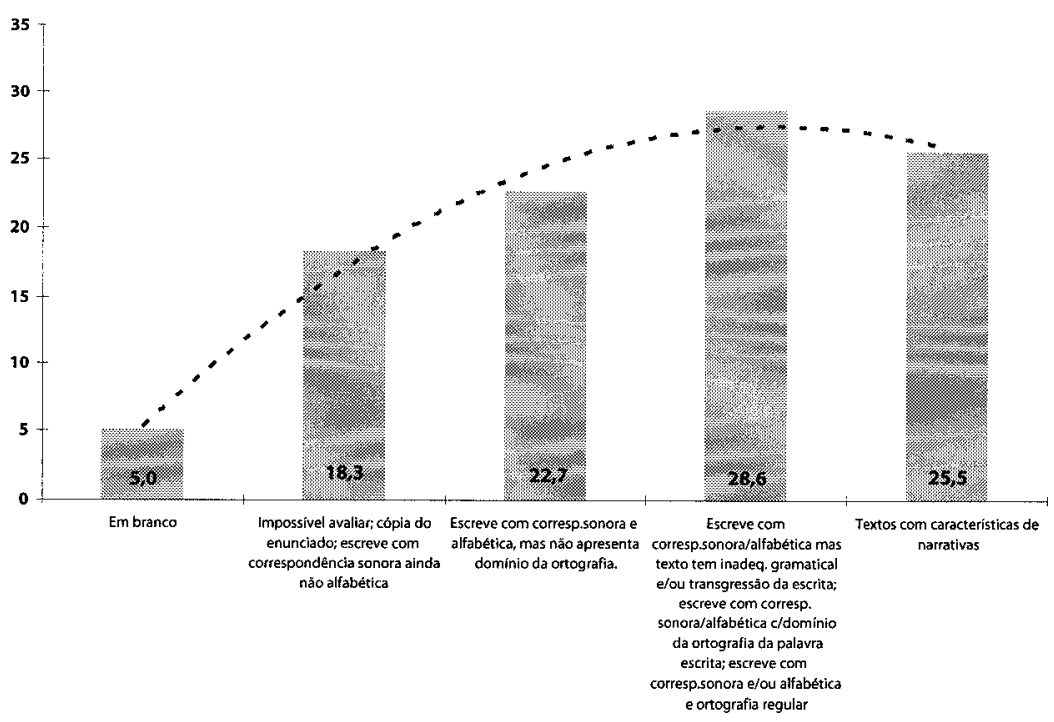




\subsection{Prova de Matemática}

Foram consideradas válidas para as análises estatísticas as provas respondidas por 1.056 alunos. Para caracterizar o desempenho dos estudantes nessa prova, foi utilizado inicialmente um procedimento de análise estatística para todas as questóes que adota como critério de apresentaçáo dos resultados a distribuição do número e do percentual de respostas, associadas às seguintes categorias: "acerto", "erro" e "em branco". A seguir, considerou-se apenas a distribuiçáo do número de acertos em cada uma das questóes, o que permitiu calcular as estatísticas gerais da prova. A prova era composta por 14 itens, três deles (itens 10,13 e 14) solicitavam duas respostas, elevando a possibilidade de acertos para 17 pontos. Os dados mostram, também, que o número mínimo de acertos foi igual a 0 (zero), e o máximo igual a 17 pontos $(100,0 \%)$. A leitura da tabela 6 mostra que a média de acertos do grupo total de participantes foi igual a 10 pontos, o que corresponde a um percentual de acertos igual a $58,2 \%$. O desvio padráo apurado ( 4,5 pontos) evidencia que o grupo de alunos era relativamente heterogêneo, em termos de desempenho.

Tabela 6 - Estatísticas gerais da prova de Matemática

\begin{tabular}{l|c}
\hline \multicolumn{1}{c|}{ Geral } & Parâmetros \\
\hline Média & 10 \\
\hline Percentiles & \\
\hline P 25 & 6 \\
\hline P 27 & 7 \\
\hline P 50 Mediana & 11 \\
\hline P 73 & 13 \\
\hline P 75 & 14 \\
\hline
\end{tabular}


O valor da mediana (11 pontos, ou 65\% acertos), superior ao valor da média (10; $58 \%$ de acertos), indica uma curva de distribuição das notas ligeiramente enviesada à direita, o que sugere que a prova foi resolvida com relativa facilidade pelo conjunto total dos participantes (Gráfico 3).

Gráfico 3 - Distribuição do número de acertos da prova de Matemática

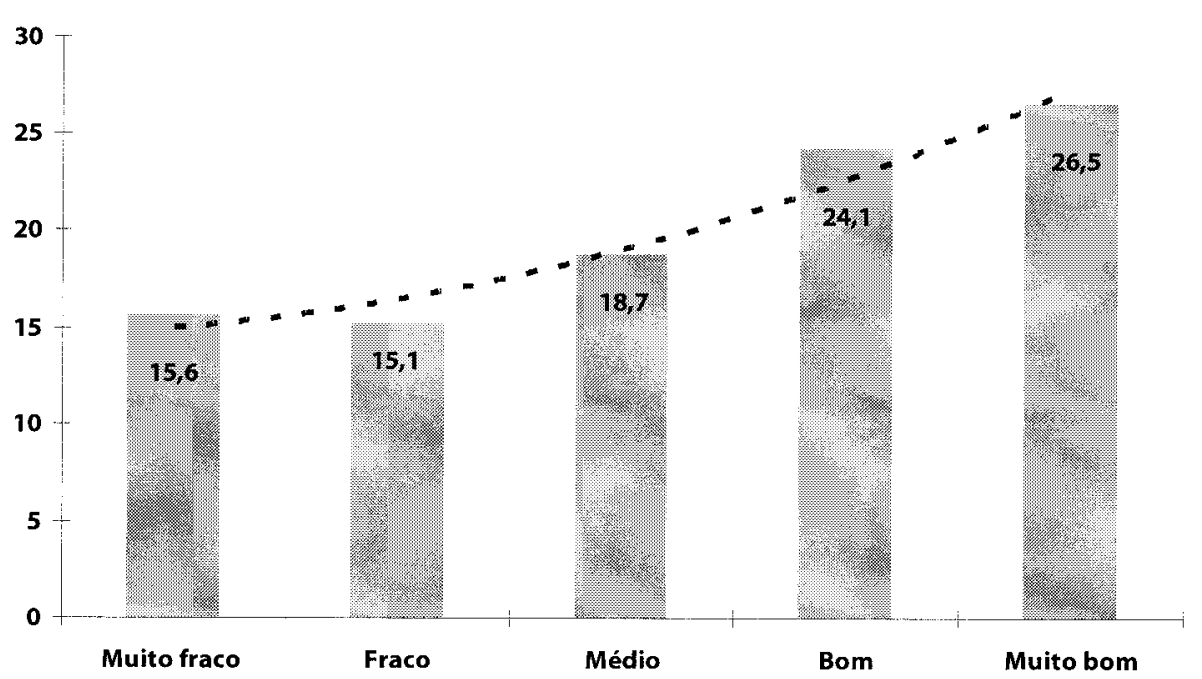

A partir dos resultados, é possível afirmar, portanto, que $70 \%$ dos alunos tiveram desempenho médio ou acima da média quanto à aquisição de competências e habilidades esperadas ao final desta etapa de escolarização. Convém ressaltar, também, que $50 \%$ dos alunos acertaram $65 \%$ da prova ou mais, e que $27 \%$ acertaram mais de $80 \%$ dos itens da prova. Esses percentuais de desempenho estão acima dos alcançados por alunos em avaliaçóes estaduais e nacionais recentes.

A matriz adotada na elaboração das questóes da prova de Matemática procurou identificar o nível de conhecimento alcançado pelos alunos, ao final das duas primeiras séries, nas habilidades e competências propostas nas diretrizes e curriculares. Para tanto, a matriz foi elaborada de forma a abranger cinco áreas de conteúdos: Números, Operaçōes, Geometria, Medidas e Estatística; cada uma delas com um número variado de descritores, como pode ser observado na tabela de especificação da prova, apresentada a seguir. 
Tabela 7 - Especificação da prova de Matemática

\begin{tabular}{|c|c|c|c|}
\hline Conteúdo & Questão & Descritor & Descritores e habilidades \\
\hline \multirow{4}{*}{ Números } & 1 & D1 & Realizar contagem de elementos de uma coleção \\
\hline & 2 & D2 & Realizar contagem de elementos e comparar coleções \\
\hline & 3 & D3 & Organizar e ordenar escritas numéricas \\
\hline & 4 & D4 & Escrever números \\
\hline \multirow{4}{*}{ Operaçōes } & 5 & D5 & Resolver situação-problema envolvendo adição \\
\hline & 6 & D6 & Calcular o resultado de uma adição com reagrupamento \\
\hline & 7 & $\overline{D 7}$ & Resolver situação-problema envolvendo subtração \\
\hline & 8 & D8 & Calcular o resultado de uma subtração com recurso \\
\hline Geometria & 9 & D9 & Identificar representação de formas geométricas tridimensionais \\
\hline \multirow{4}{*}{ Medidas } & 10a & D10 & Efetuar leitura de informações contidas em calendário \\
\hline & $10 \mathrm{~b}$ & D10 & Efetuar leitura de informações contidas em calendário \\
\hline & 11 & D11 & $\begin{array}{l}\text { Resolver situação-problema envolvendo a identificação do valor } \\
\text { de cédulas do sistema monetário brasileiro }\end{array}$ \\
\hline & 12 & D12 & $\begin{array}{l}\text { Resolver situação-problema envolvendo a identificação do valor } \\
\text { de moedas do sistema monetário brasileiro }\end{array}$ \\
\hline \multirow{4}{*}{ Estatística } & $13 a$ & D13 & $\begin{array}{l}\text { Resolver situação-problema envolvendo a leitura de dados } \\
\text { dispostos em tabelas }\end{array}$ \\
\hline & $13 b$ & D13 & $\begin{array}{l}\text { Resolver situação-problema envolvendo a leitura de dados } \\
\text { dispostos em tabelas }\end{array}$ \\
\hline & $14 a$ & D14 & $\begin{array}{l}\text { Resolver situação-problema envolvendo a leitura de dados } \\
\text { dispostos em gráficos de barras }\end{array}$ \\
\hline & $14 b$ & D14 & $\begin{array}{l}\text { Resolver situação-problema envolvendo a leitura de dados } \\
\text { dispostos em gráficos de barras }\end{array}$ \\
\hline
\end{tabular}

Para cada uma das questóes, calculou-se separadamente o percentual de acertos para a amostra total, assim como para o grupo superior e inferior de alunos, conforme definido no agrupamento das escolas. A diferença de desempenho entre os grupos extremos permitiu detectar o índice de discriminação de cada um dos itens e sua composiçáo na organização da prova (Tabela 8). 
Tabela 8 - Percentual de respostas certas por grupos de desempenho em Matemática

\begin{tabular}{|c|c|c|c|c|c|c|c|c|c|}
\hline \multirow{2}{*}{ Itens } & \multicolumn{2}{|c|}{ Inferior } & \multicolumn{2}{|c|}{ Intermediário } & \multicolumn{2}{|c|}{ Superior } & \multicolumn{2}{|c|}{ Total } & \multirow{2}{*}{$\begin{array}{c}\text { Diferença } \\
\%\end{array}$} \\
\hline & $\mathbf{n}$ & $\%$ & $\mathbf{n}$ & $\%$ & $n$ & $\%$ & $n$ & $\%$ & \\
\hline$q 1$ & 166 & 51 & 393 & 87 & 266 & 95 & 825 & 78 & 44 \\
\hline $\mathrm{q}^{2}$ & 223 & 69 & 424 & 94 & 276 & 99 & 923 & 87 & 30 \\
\hline q3 & 45 & 14 & 323 & 72 & 267 & 95 & 635 & 60 & 82 \\
\hline q4 & 33 & 10 & 278 & 62 & 267 & 95 & 578 & 55 & 85 \\
\hline q5 & 52 & 16 & 282 & 62 & 263 & 94 & 597 & 57 & 78 \\
\hline q6 & 16 & 5 & 161 & 36 & 261 & 93 & 438 & 42 & 88 \\
\hline q7 & 21 & 7 & 238 & 53 & 255 & 91 & 514 & 49 & 85 \\
\hline q8 & 6 & 2 & 63 & 14 & 181 & 65 & 250 & 24 & 63 \\
\hline q9 & 179 & 55 & 383 & 85 & 257 & 92 & 819 & 78 & 37 \\
\hline q10a & 78 & 24 & 369 & 82 & 274 & 98 & 721 & 68 & 74 \\
\hline q10b & 39 & 12 & 305 & 68 & 267 & 95 & 611 & 58 & 83 \\
\hline$q 11$ & 84 & 26 & 344 & 76 & 273 & 98 & 701 & 66 & 72 \\
\hline$q 12$ & 46 & 14 & 153 & 34 & 182 & 65 & 381 & 36 & 51 \\
\hline q13a & 178 & 55 & 428 & 95 & 279 & 100 & 885 & 84 & 45 \\
\hline$q 13 b$ & 34 & 11 & 279 & 62 & 259 & 93 & 572 & 54 & 82 \\
\hline q14a & 160 & 49 & 407 & 90 & 275 & 98 & 842 & 80 & 49 \\
\hline$q 14 b$ & 5 & 2 & 46 & 10 & 126 & 45 & 177 & 17 & 44 \\
\hline
\end{tabular}

A análise do desempenho na prova de Matemática indicou que para o grupo total de participantes sete questóes foram resolvidas com facilidade $(66 \%$ a $85 \%$ dos alunos acertaram cada um desses itens), ou com muita facilidade ( $86 \%$ a $100 \%$ de acertos); oito questóes foram solucionadas com dificuldade mediana para o grupo (36\% a $65 \%$ dos alunos acertaram cada item); e $12 \%$, ou duas questóes, foram difíceis para o grupo (16\% a 35\% de alunos acertaram). Nenhuma questão foi considerada muito difícil, ou seja, acertada por menos de $16 \%$ dos alunos da amostra total. Esses resultados aparecem na tabela 9. 
Tabela 9 - Classificação da dificuldade dos itens

\begin{tabular}{l|c|c|c|c|c}
\hline \multirow{2}{*}{ Classificação } & \multirow{2}{*}{$\begin{array}{c}\text { \% de } \\
\text { acertos }\end{array}$} & $\begin{array}{c}\mathbf{N}^{\circ} \text { de } \\
\text { itens }\end{array}$ & $\begin{array}{c}\text { Identificação do } \\
\mathbf{n}^{\circ} \text { do item }\end{array}$ & $\begin{array}{c}\mathbf{N}^{\circ} \text { de } \\
\text { itens }\end{array}$ & $\begin{array}{c}\text { Identificação do } \\
\mathbf{n}^{\circ} \text { do item }\end{array}$ \\
\hline Muito fácil & 86 a 100 & 1 & 2 & & \\
\hline Fácil & 66 a 85 & 6 & $\begin{array}{c}1,9,10 a, 11,13 a \\
14 a\end{array}$ & 1 & 2 \\
\hline Mediano & 36 a 65 & 8 & $\begin{array}{c}3,4,5,6,7,10 b, \\
12,13 b\end{array}$ & 3 & $9,13 a, 14 a$ \\
\hline Difícil & 16 a 35 & 2 & $8,14 \mathrm{~b}$ & 3 & $5,10 \mathrm{a}, 11$ \\
\hline Muito difícil & 0 a 15 & 0 & & 10 & $\begin{array}{c}1,3,4,6,7,8, \\
10 \mathrm{~b}, 12,13 \mathrm{~b}, 14 \mathrm{~b}\end{array}$ \\
\hline
\end{tabular}

O conjunto das estatísticas revela uma prova bem balanceada, com diversidade de desempenho no interior da amostra e presença de itens com altos índices de discriminação, capazes de detectar diferença entre os grupos. Portanto, adequada aos objetivos da avaliação.

Foram calculados os coeficientes de correlaçáo de Spearman entre as provas de Leitura e Matemática, Leitura e Redação e Matemática e Redação. Os resultados, apresentados na tabela 10, mostram que é alto o índice de correlaçáo encontrado entre as diferentes provas. Percebe-se, portanto, grande coerência de desempenho dos alunos nas três provas, o que demonstra respostas náo casuísticas e resultados fortemente imbricados nessas áreas.

Tabela 10 - Correlação entre o desempenho dos alunos em Leitura, Matemática e Redação

\begin{tabular}{l|c|c}
\hline \multicolumn{1}{c|}{ Provas } & $\begin{array}{c}\text { Coeficientes de } \\
\text { correlação }\end{array}$ & N \\
\hline Leitura e Matemática & 0,8 & 1020 \\
\hline Leitura e Redação & 0,7 & 1023 \\
\hline Matemática e Redação & 0,7 & 1005 \\
\hline
\end{tabular}




\section{EXPECTATIVAS EM RELAÇÃO AO PROJETO EDUCA+AÇÃO}

\subsection{Dos professores}

A fim de captar a percepçáo dos professores quando o projeto teve início e verificar se, ao final, suas expectativas haviam sido confirmadas, foram apresentadas questóes abertas para que pudessem expor sua opinião.

Em relaçâo às expectativas no início do projeto, $63 \%$ dos professores afirmaram que elas eram positivas. Entre eles, $21 \%$ afirmaram que sua expectativa era obter resultados produtivos e satisfatórios com os alunos, melhor dito, apontam aspectos relacionados com o desempenho discente, por exemplo, com a alfabetização; outros $29 \%$ manifestaram que sua expectativa no início do projeto era ampliar seu desenvolvimento profissional: "adquirir novas experiências e desenvolvê-las em sala de aula; contribuir para a minha formação profissional; adquirir novos conhecimentos e práticas; um desafio a mais para minha vida profissional; aprender sempre novas metodologias". Ao final do projeto, ao serem perguntados sobre suas expectativas, $77 \%$ dos professores disseram que elas haviam se confirmado; $13 \%$ que foram confirmadas "em parte"; e 6\% afirmaram que elas não se confirmaram.

Um aspecto essencial da avaliação do Projeto Educa+Ação era verificar se a percepção dos professores era a de que ele contribuiu para eventuais mudanças em sua prática pedagógica. A maioria dos professores (88\%) afirmou que houve mudanças em sua prática de sala de aula em decorrência das ações do projeto. Um contingente pouco representativo (8\%) disse que isso não ocorreu.

\subsection{Dos diretores}

Com o objetivo de avaliar o projeto sob a ótica dos diretores, traçar um perfil do grupo, analisar suas expectativas em relaçáo à contribuição efetiva do Educa+Ação sobre o desempenho dos alunos, avaliar a prática de sala de aula dos professores, e a mudança nas propostas pedagógicas da escola e na sua gestão, eles foram convidados a responder um questionário abrangendo 41 itens de questóes fechadas e abertas.

Todos os diretores das 14 escolas do Projeto Educa+Ação responderam aos questionários entregues pelas pesquisadoras e, por meio das respostas, verificou-se que um número significativo (86\%) declarou que suas expectativas em relação ao projeto haviam se confirmado; para alguns os resultados superaram as expectativas iniciais (36\%). Do mesmo modo, 93\% concordam que o Projeto Educa+Ação contribuiu para mudar sua prática de gestâo, relacionando várias mudanças importantes para esse aprimoramento. 


\subsection{Dos pais}

O Projeto Educa+Ação previa não só que os profissionais da escola conhecessem e se envolvessem com ele, mas também que os pais fossem esclarecidos sobre a nova metodologia e os novos materiais que seriam destinados a seus filhos. O Instituto Protagonistés realizou 17 grupos focais com 203 pais ou responsáveis pelos alunos, para avaliar se os pais haviam sido informados da participaçáo da classe dos seus filhos no projeto e qual a sua percepçáo sobre alguns materiais e a aprendizagem das crianças. As mães continuam sendo, em geral, as representantes dos filhos perante a escola com $89 \%$ de participação; seguida dos pais (7\%) e outros parentes (4\%). Todos os presentes afirmaram que sabiam que seus filhos iram participar de um projeto da Fundação Bradesco, pois foram informados em reunião promovida anteriormente pela escola.

O gráfico 4 ilustra as expectativas quanto ao programa Educa+Ação, manifestadas pelos pais dos grupos focais:

Gráfico 4 - Distribuição da expectativa dos pais

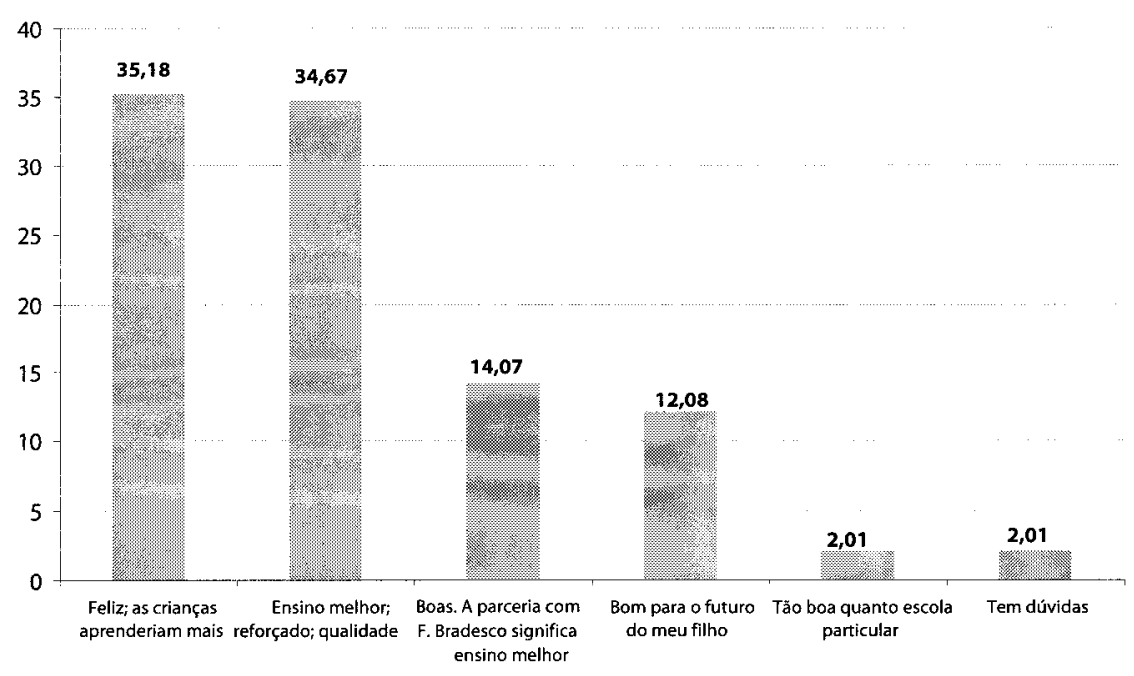

\section{FATORES ASSOCIADOS QUE INFLUENCIARAM OS RESULTADOS 5.1 Características dos alunos}

Com o objetivo de verificar quais as características dos alunos que estão mais fortemente associadas ao seu desempenho e possibilitar intervençóes específicas para a melhoria da qualidade do ensino-aprendizagem, procedeu-se a dois diferentes tipos 
de processamento dos resultados da prova de Leitura. Num primeiro momento, os resultados obtidos foram tabulados para verificar as médias dos alunos, em funçáo das características individuais dos estudantes (sexo, idade, cor/etnia, frequência à pré-escola e reprovação escolar). Em seguida, foram efetuadas análises de variância (ANOVA) para detectar se as diferenças entre as médias dos grupos para cada uma das características individuais (por exemplo, meninos ou meninas, no caso de sexo) eram estatisticamente significantes, ou seja, se aquelas características estavam ou não associadas, e se influenciavam o desempenho dos alunos.

A idade dos alunos foi apurada em janeiro de 2008, no segundo ano do Projeto Educa+Ação (Tabela 11). Chama especial atenção a presença de crianças com até 6 anos e meio à época, ou seja, elas teriam começado a participar do projeto com 5 a 5 anos e meio, idade em que deveriam estar cursando a pré-escola. Os resultados mostram que essas crianças obtiveram média pior do que a dos outros grupos, e $20 \%$ mais baixa do que a do grupo na faixa etária correta, aqueles com mais de 7,5 anos na segunda série, que iniciaram o ensino fundamental com cerca de 6 a 6 anos e meio. A falta de maturidade cognitiva, a ausência de maior permanência na pré-escola, a falta de uma definiçáo curricular pela antecipação da escolaridade que ocorreu com o grupo mais jovem são fatores que claramente influenciaram o desempenho desses alunos, principalmente se forem tratados como crianças preparadas para cursar o currículo da primeira ou segunda séries do antigo ensino fundamental.

Tabela 11 - Médias na prova de Leitura e distribuição do número de alunos, segundo a idade

\begin{tabular}{l|c|c|c}
\multicolumn{1}{c|}{ Idade } & Média & N & $\%$ \\
\hline Até 6,5 anos & 20,5 & 309 & 30 \\
\hline Mais que 6,5 a 7,5 & 22,9 & 508 & 49 \\
\hline Mais que 7,5 & 25,1 & 228 & 22 \\
\hline Total & 22,7 & 1045 & 100 \\
\hline
\end{tabular}




\subsection{Características dos professores}

Em relaçáo às características e percepçóes dos professores mais fortemente associadas ao desempenho dos alunos e com o objetivo de delinear futuras intervençóes para a melhoria da qualidade do ensino-aprendizagem procedeu-se às análises estatísticas de forma bastante semelhante à relatada para as características individuais dos alunos. Foram efetuadas análises de variância (ANOVA) para verificar se as diferenças entre as médias dos grupos para cada uma das características ou percepçōes dos professores (por exemplo, se haviam cursado segundo grau ou terceiro grau; se eram do sexo masculino ou feminino; se haviam acompanhado ou não a classe desde o início do projeto) eram estatisticamente significantes, ou seja, se essas características influenciavam o desempenho dos alunos, e se estavam ou não associadas a ele.

A análise de variância revelou que algumas características e percepçóes dos professores estavam associadas a diferentes desempenhos dos alunos, entre elas: faixa etária; escolaridade; frequência a um curso de pós-graduação; experiência na primeira série; carga horária total das atividades de formaçâo continuada; se foi a professora da classe desde 2007; por que acha que sua classe foi escolhida; se usou os DVDs de Língua Portuguesa, História e Ciência; se utilizou pouco, ou não utilizou as apostilas dos alunos.

\section{CONCLUSÃO}

Os resultados indicam que o desempenho dos alunos nas diferentes provas está acima da média das avaliaçôes estaduais e nacionais recentes e são altamente consistentes. Com base no conjunto de variáveis, consideradas estatisticamente significantes para diferenciar o desempenho de diferentes grupos de alunos, a análise estatística (testes específicos) possibilitou concluir que algumas características dos alunos e dos professores foram relevantes para os resultados do projeto, entre elas: a idade dos alunos e a frequencia à pré-escola. No caso dos professores, destacam-se: possuir nível superior, não necessariamente Pedagogia; permanência nos dois anos do projeto piloto e o conhecimento e envolvimento na proposta do projeto.

Esta avaliaçáo confirmou que os pontos fortes deste trabalho foram: os momentos de capacitaçáo, que garantiram a compreensão da proposta pedagógica e o uso do material didático; o apoio da equipe técnica da Fundação Bradesco nas visitas às escolas; a permanência do professor por dois anos na mesma classe e os recursos e materiais pedagógicos de qualidade. 
Sabe-se que mudar práticas de gestáo e de sala de aula não é fácil. De fato, diretores e professores parecem compreender essa dificuldade ao interpretar como positivas as açóes que contribuíram para a mudança de sua prática pedagógica em sala de aula, o conhecimento adquirido nas capacitaçóes e as habilidades desenvolvidas durante o projeto, o que lhes despertou a criatividade e a autoconfiança para inovar com ousadia e segurança.

\section{REFERÊNCIAS BIBLIOGRÁFICAS}

GUILFORD, J. P. Psychometric methods. $2^{\text {nd }}$ ed. New York: McGraw-Hill, 1954.

Fundamental statistics in psychology and education. New York: McGrawHill, Book Company, 1956.

OCDE-PISA. Ministério da Educação. Instituto Nacional de Estudos e Pesquisas Educacionais Anísio Teixeira (Inep). Programa Internacional de Avaliação de Alunos (PISA). Resultados Nacionais - PISA 2006. Brasília/ DF, 2008.

PROTAGONISTÉS. INSTITUTO DE PROTAGONISMO JOVEM E EDUCAÇÃO. Avaliação do projeto gestão para o sucesso escolar. Projeto de formação e capacitação online. São Paulo: Fundação Lemann; Protagonistés, fev. 2003 a mar. 2005.

Avaliação do rendimento escolar dos alunos de $2^{a} 5,4^{a} s, 6^{a} 5$ e $8^{a} s$ séries da Rede Municipal de Ensino, em Língua Portuguesa e Matemática, de Campo Limpo Paulista/SP. São Paulo: Protagonistés, jul. 2006 a jan. 2007.

ASSESSMENT SYSTEMS CORPORATION. User's Manual for Iteman. The Iteman TM Conventional Item Analysis Program 1989-1996. $2^{\text {nd }} e d$. Assessment Systems Corporation [1996]. 